\title{
Impact of diabetes mellitus on coagulation function before and after off-pump coronary artery bypass grafting
}

\author{
Dawei Wang ${ }^{1}$, Yu Liu ${ }^{2}$, Ziying Chen ${ }^{2}$, Fei Yang ${ }^{3}$, Zhenming Zhang ${ }^{1}$, Yulei Wei ${ }^{1}$ \\ ${ }^{1}$ Department of Cardiothoracic Surgery, The First Affiliated Hospital of Hebei North University, Zhangjiakou 075000, China; ${ }^{2}$ Department of \\ Cardiac Surgery, The Second Hospital of Hebei Medical University, Shijiazhuang 050000, China; ${ }^{3}$ Department of Medical Imaging, The First \\ Affiliated Hospital of Hebei North University, Zhangjiakou 075000, China \\ Contributions: (I) Conception and design: D Wang, Y Liu, Z Chen; (II) Administrative support: F Yang, Z Zhang; (III) Provision of study materials \\ or patients: Z Zhang, Y Wei; (IV) Collection and assembly of data: Z Zhang, Y Wei; (V) Data analysis and interpretation: D Wang, Y Liu; (VI) \\ Manuscript writing: All authors; (VII) Final approval of manuscript: All authors. \\ Correspondence to: Ziying Chen, MD. Department of Cardiac Surgery, The Second Hospital of Hebei Medical University, No. 215 of Hepingxi Road, \\ Shijiazhuang 050000, China. Email: chenziying303@163.com.
}

Background: This study aims to explore the influence of off-pump coronary artery bypass grafting (OPCABG) on coagulation function and the effects of diabetes on coagulation function during OPCABG.

Methods: Patients who met the inclusion and exclusion criteria were divided into two groups: diabetes mellitus (DM) and non-diabetes mellitus (NDM) groups. Thromboelastography (TEG) was tested at the following time points: T0, five days after aspirin and clopidogrel therapy, and before OPCABG; T1, returning to care unit after OPCABG; T2, 5 days after aspirin and clopidogrel therapy, and after OPCABG.

Results: A total of 56 patients were involved. There were no deaths, or no early postoperative thrombotic events and abnormal bleeding after OPCABG. Intra-group comparison: Compared with T0, the R and $\mathrm{K}$ value decreased, while the $\alpha$ angle and MA value increased at $\mathrm{T} 1$ and $\mathrm{T} 2$, in both groups $(\mathrm{P}<0.05)$. A significantly statistical difference was found in the multiple comparison at T0, T1 and T2 $(\mathrm{P}<0.05)$. The results are as follows: the $\mathrm{R}$ value decreased at $\mathrm{T} 1$ and increased at $\mathrm{T} 2$, but the value remained less than that at T0. After the OPCABG, the K value gradually decreased, while the MA value and $\alpha$ angle gradually increased. Comparison between groups: T1: the R values were lower in the DM group, when compared to the NDM group ( $\mathrm{t}=3.611, \mathrm{P}=0.001)$. The differences in the MA, $\mathrm{K}$ and $\alpha$ angle were not statistically significant. T0 and T2: there were no statistically difference in the R, MA, K, $\alpha$ angle and LY30 between the two groups $(\mathrm{P}>0.05)$.

Conclusions: The coagulation function of patients was at a hypercoagulable state at the early stage after OPCABG. The coagulation function was affected by diabetes at the day of OPCABG. However, there was no statistical difference after 5 days of aspirin and clopidogrel therapy following OPCABG.

Keywords: Coronary artery bypass grafting; off-pump coronary artery bypass grafting (OPCABG); thromboelastography (TEG); coagulation function; diabetes mellitus (DM)

Submitted Jul 19, 2019. Accepted for publication Oct 31, 2019.

doi: $10.21037 /$ jtd.2019.11.27

View this article at: http://dx.doi.org/10.21037/jtd.2019.11.27 


\section{Introduction}

In recent years, off-pump coronary artery bypass grafting (OPCABG) has been widely used in the surgical treatment of coronary heart disease. OPCABG without using a cardiopulmonary artery bypass $(\mathrm{CPB})$ can present the influence of extracorporeal circulation on the human body, may present a number of complications, such as post-procedure myocardial, pulmonary, renal and cerebral complications, and better protect the coagulation mechanism, but may increase the risk of postoperative thrombosis (1-3). It is known that the postoperative graft of vascular stenosis and occlusion eventually leads to serious cardiovascular events, such as myocardial ischemia and myocardial infarction, which result in increased patient mortality. In the early period of postoperation, thrombosis is an important factor that leads to the blockage of grafted vessels, which in turn is closely correlated to thrombosis and coagulation function $(1,4)$. Therefore, the accurate and timely monitoring of coagulation changes in patients, and effective anti-platelet therapy is of significant value to reduce blood vessel thrombosis in the perioperative period.

Gradually, people have realized that the occurrence and development of diabetes and coagulation fibrinolysis system imbalance are inextricably linked. Studies have found that coagulation enhancement and platelet reactivity increase occur in diabetes patients at the early stages (5). However, the risk of cardiovascular disease is two times higher among individuals with diabetes, when compared to those without diabetes (6). Thus, the present study of coagulation function in patients with coronary heart disease combined with diabetes during the OPCABG perioperative period has significant clinical value. This provides an important guideline for the rational antiplatelet therapy for these patients, in order to reduce the risk of cardiovascular complications, thrombotic recurrence and adverse outcomes.

In the past few years, thromboelastography (TEG) has been widely used for blood coagulation function monitoring, surgery, antiplatelet efficacy assessment and platelet resistance screening in patients with cardiovascular disease. TEG can provide the entire process information of coagulation function through the graphical display (7), including the start of coagulation function, the platelet junction, fibrin filament formation, blood clot formation and growth, the largest blood clot formation, and the dissolution of terminal blood clots. Through these TEG parameters, the physical characteristics of blood clots, such as formation rate, intensity and stability, can be assessed, and the patient's coagulation function can be determined (8). Compared with the monitoring technology method used in clinic, TEG is closer to the whole process of clotting occurrence and development in a patient's body, and can rapidly and thoroughly reflect the clotting and hemolysis process in a short period of time.

The aim of the present prospective study was to compare the changes in blood coagulation before and after OPCABG in diabetic and non-diabetic patients using TEG, in order to determine the influence of OPCABG and the impact of diabetes mellitus (DM) on coagulation function in patients undergoing OPCABG. This can provide meaningful guidance for the rational application of antiplatelet therapy in OPCABG patients with coronary heart disease and DM during the perioperative period.

\section{Methods}

\section{Study subjects}

Patients with coronary heart disease, who were treated with OPCABG in our hospital for the first time from December 2015 to January 2017, were collected.

Inclusion criteria: (I) patients who underwent OPCABG; (II) patients whose preoperative routine examinations were within the normal range, and patients who met the OPCABG indications; (III) patients with no history of blood system disease; (IV) patients with no history of mental illness; (V) patients approved by the Hospital Ethics Committee to participate in the present study for scientific research, and patients who provided a signed informed consent.

Exclusion criteria: (I) patients with clopidogrel and aspirin contraindications; (II) patients who were turned into extracorporeal circulation during surgery; (III) patients with a history of tumor, and long-term use of chemotherapy and immunosuppressive agents; (IV) patients combined with valvular disease or other heart diseases that require simultaneous surgery, or the intraoperative or postoperative input of platelet products; $(\mathrm{V})$ patients with a previous history of cardiac surgery (including stenting) and emergency surgery; (VI) patients in the preoperative inflammation state (severe infections, arthritis activity, cancer, etc.), and patients receiving other anti-inflammatory analgesic drugs that can affect platelet function; (VII) patients with the activity stage of digestive ulcer, hemophilia 
and other low-thrombin hyper thrombin.

Aspirin and clopidogrel were stopped three days before the operation. Then, two days after the operation, oral aspirin at $100 \mathrm{mg} / \mathrm{d}$ and clopidogrel at $75 \mathrm{mg} / \mathrm{d}$ were given to these patients for more than five days.

The basic information and relevant clinical data during the hospitalization of these patients were collected, such as age, gender, height, weight, smoking, history of myocardial infarction, hypertensive history, total triglyceride, total cholesterol and coronary lesion vessels, before the operation. The number of grafted blood vessels, and intraoperative and postoperative drainage were also recorded.

According to the diagnostic criteria for type-2 DM by the European Society of Cardiology (ESC) and the European Association for the Study of Diabetes (EASD) in 2013 (9), patients who met the inclusion criteria and exclusion criteria were divided into two groups: DM group and non-DM (NDM) group.

\section{Surgical procedure}

All surgeries were performed by the same surgeon. Intravenous anesthesia with fentanyl and propofol, and inhalation of isoflurane for general anesthesia were given. During the endotracheal intubation, the respiratory tidal volume was $8-10 \mathrm{~mL} / \mathrm{kg}$, respiratory rate was $12-16 \mathrm{bpm}$, suction-to-expiratory ratio was $1: 2$, carbon dioxide partial pressure was $35-45 \mathrm{mmHg}$, average arterial pressure was $60-90 \mathrm{mmHg}$, and heart rate was $50-80 \mathrm{bpm}$. The left internal mammary artery and great saphenous vein were used as the grafted vessel. After the grafted blood vessels were collected, the whole body was heparinized $(100 \mathrm{U} / \mathrm{kg})$. Then, the activated coagulation time of whole blood [activated clotting time (ACT)] was closely monitored. An ACT of $>300$ seconds was generally maintained during the surgery, and heparin was timely adjusted according to the ACT value. The heparin was antagonistic with protamine at 1:1 after the operation, in order to enable the ACT to resume preoperative levels. The recovered blood was used during the operation.

\section{Experimental equipment}

Instrument: Thromboelastography [5000], provided by Haemoscope Corporation. Reagent: kaolin, activator F, supplied by Haemoscope.

\section{Specimen collection}

The venous blood of patients in the two groups were collected at three time points: T0, oral aspirin at $100 \mathrm{mg} / \mathrm{d}$ and clopidogrel at $75 \mathrm{mg} / \mathrm{d}$ were preoperatively given for more than five days; T1, return to the intensive care unit after the operation; T2, aspirin at $100 \mathrm{mg} / \mathrm{d}$ and clopidogrel at $75 \mathrm{mg} / \mathrm{d}$ after the operation for more than five days. Next, the collected blood was detected by TEG, and indexes, such as the $\mathrm{R}$ value, $\mathrm{K}$ value, $\alpha$ angle, MA value and LY30, were observed and analyzed.

\section{TEG index}

* Reaction time (R): time from the start of the recording until the amplitude reaches $2 \mathrm{~mm}$.

* Coagulation time (K): time from the end of the reaction time until the amplitude reaches $20 \mathrm{~mm}$.

* Maximum amplitude (MA): the maximum width of the TEG trace represents the absolute strength of the clot.

- Angle $(\alpha)$ : formed by the slope from the $\mathrm{R}$ value to the $\mathrm{K}$ value.

- LY30: the amplitude attenuation rate of 30 minutes after maximum amplitude.

\section{Research indicators}

The perioperative changes of coagulation function of OPCABG patients in the DM and NDM groups were compared by TEG. The influence of OPCABG on coagulation function and the effect of DM on coagulation function in patients with OPCABG were analyzed, in order to provide meaningful guidance for the "individualized" antiplatelet therapy of coronary heart disease patients with $\mathrm{DM}$ in the perioperative period of OPCABG.

\section{Statistical analysis}

Data analysis was performed using the SPSS 17.0 statistical software package (SPSS Inc., Chicago, IL, USA). Quantitative data were expressed as mean \pm standard deviation (SD). Normality and variance homogeneity tests were used for the main statistical indicators. Independent test was used to compare the data between the two groups. Variance analysis was used to compare the data between multiple groups. Categorical variables were expressed as frequencies or percentage, and the data were compared using $\chi^{2}$-test. Significance was assessed by two-tailed test, 
and $\mathrm{P}<0.05$ was considered statistically significant.

\section{Results}

Comparison of the main clinical data between the DM and NDM groups

A total of 56 patients were enrolled in the present study.

DM group: 30 patients (19 male), with an average age of $63.40 \pm 7.60$ years old. NDM group: 26 patients (17 males), with an average age of $61.92 \pm 9.40$ years old.

The preoperative blood glucose was higher in the DM group $(6.47 \pm 1.73)$ than in the NDM group $(5.09 \pm 0.91)$. The remaining main clinical data, such as age, gender, body mass index (BMI), smoking history, myocardial infarction history, hypertensive history, total triglyceride, total cholesterol and number of coronary artery lesions, were compared between the two groups, and there was no significant difference between these two groups $(\mathrm{P}>0.05$, Table 1).

There were no deaths, and no postoperative thrombotic events and abnormal bleeding in both groups.

\section{Changes in coagulation function of TEG in the DM and NDM groups before and after OPCABG}

Intra-group comparison: Comparison of TEG parameters before and after the operation in the DM and NDM groups

\section{DM group}

Compared with the preoperative $\mathrm{T} 0$ time point, the $\mathrm{R}$ and $\mathrm{K}$ values decreased, while the $\alpha$ angle and MA value increased at the postoperative $\mathrm{T} 1$ and $\mathrm{T} 2$ time points, and the difference was statistically significant. Furthermore, there was a significant difference between each two of these time points $(\mathrm{P}<0.05)$. The change rule is presented in Figures 1-4: the $\mathrm{R}$ value decreased at the $\mathrm{T} 1$ time point and increased at the $\mathrm{T} 2$ time point, but remained less than the value at the T0 time point. The $\mathrm{K}$ value gradually decreased after surgery, while the $\alpha$ angle and MA value gradually increased after surgery. LY30 was zero at each group (Table 2).

\section{NDM group}

Compared with the preoperative $\mathrm{T} 0$ time point, the $\mathrm{R}$ and $\mathrm{K}$ values decreased, while the $\alpha$ angle and MA value increased at the postoperative $\mathrm{T} 1$ and $\mathrm{T} 2$ time points, and the difference was statistically significant. Furthermore, there was a significant difference between each two of the groups $(\mathrm{P}<0.05)$. The change rule is reflected in Figures 1-4: the $\mathrm{R}$ value decreased at the $\mathrm{T} 1$ time point and increased at the T2 time point, but remained less than the value at the T0 time point. The $\mathrm{K}$ value gradually decreased after surgery, while the $\alpha$ angle and MA value gradually increased after surgery. However, there was no statistically significant difference in LY30 at each time point $(\mathrm{P}=0.797$, Table 3).

\section{Comparison between groups: comparison of} coagulation function between the DM and NDM groups before and after the operation Comparative analysis of coagulation function between the DM and NDM groups at the preoperative T0 time point (Table 4)

There were no significant differences in $\mathrm{R}$ value, MA value, $\mathrm{K}$ value and $\alpha$ angle between the DM and NDM groups at the preoperative T0 time point $(\mathrm{P}>0.05)$.

Comparison of coagulation function between the DM and NDM groups at the T1 time point (Table 5)

After returning to the intensive care unit, the $\mathrm{R}$ value was significantly lower in the DM group than in the NDM group, and the difference was statistically significant. However, the difference in MA value, $\mathrm{K}$ value and $\alpha$ angle was not statistically significant $(\mathrm{P}>0.05)$.

Comparison of coagulation function between the DM and NDM groups at the T2 time point (Table 6)

Aspirin at $100 \mathrm{mg} / \mathrm{d}$ and clopidogrel at $75 \mathrm{mg} / \mathrm{d}$ for more than five days after the operation: the difference in $\mathrm{R}$ value, MA value, $\mathrm{K}$ value and $\alpha$ angle was not statistically significant between the DM and NDM groups $(\mathrm{P}>0.05)$.

\section{Discussion}

\section{Statement of principal findings}

The present study revealed that the coagulation function of patients was at a hypercoagulable state at the early stage after OPCABG. The coagulation function was affected by diabetes at the day of OPCABG. However, there was no statistical difference after five days of aspirin and clopidogrel therapy following OPCABG.

\section{Discussion of the principal findings in relation to other studies (important differences in the results)}

\section{Effect of OPCABG on coagulation function}

At present, the general view is that OPCABG without extracorporeal circulation can prevent mechanical damage, low temperature and many other factors that may damage normal blood components in the process of 
Table 1 Comparison of main clinical data of DM group and NDM group

\begin{tabular}{|c|c|c|c|}
\hline Variable & $\mathrm{DM}(\mathrm{n}=30)$ & NDM $(n=26)$ & $\mathrm{P}$ \\
\hline Age (year) & $63.40 \pm 7.60$ & $61.92 \pm 9.40$ & 0.52 \\
\hline MI (\%) & $3(10.00)$ & $3(11.54)$ & 0.85 \\
\hline Smoker (\%) & $14(46.67)$ & $9(34.62)$ & 0.42 \\
\hline Statins (\%) & $30(100)$ & $25(96.15)$ & 0.46 \\
\hline$\beta$-blockers (\%) & 29 (96.67) & $25(96.15)$ & 1.0 \\
\hline ACE inhibitors (\%) & $1(3.33)$ & $3(11.54)$ & 0.39 \\
\hline PPIs (\%) & $2(6.67)$ & $0(0.00)$ & 0.49 \\
\hline Triple vessel disease (\%) & $27(90.00)$ & $23(88.46)$ & 1.0 \\
\hline Left Main Disease (\%) & $17(56.67)$ & $12(46.15)$ & 0.59 \\
\hline BMI $\left(\mathrm{kg} / \mathrm{m}^{2}\right)$ & $25.84 \pm 2.00$ & $24.93 \pm 3.70$ & 0.25 \\
\hline $\operatorname{PLT}\left(\times 10^{9} / \mathrm{L}\right)$ & $214.57 \pm 45.05$ & $204.69 \pm 51.25$ & 0.45 \\
\hline TG (mmol/L) & $2.06 \pm 1.03$ & $1.69 \pm 0.66$ & 0.13 \\
\hline LDL-c (mmol/L) & $2.31 \pm 0.80$ & $2,57 \pm 1.19$ & 0.33 \\
\hline HDL-c (mmol/L) & $0.94 \pm 0.21$ & $1.07 \pm 0.28$ & 0.06 \\
\hline Blood glucose & $6.47 \pm 1.73$ & $5.09 \pm 0.91$ & 0.001 \\
\hline
\end{tabular}

DM, diabetes mellitus; NDM, non-diabetes mellitus; MI, myocardial infarction; ACE, angiotensin converting enzyme; PPIs, proton pump inhibitors; PCI, percutaneous coronary intervention; BMI, body mass index; PLT, platelet; TG, triglyceride; LDL-c, low-density lipoprotein cholesterol; HDL-c, high density lipoprotein cholesterol

the extracorporeal circulation, and this would be helpful in reducing postoperative complications. According to research reports (10), and regardless of the efforts to improve the biocompatibility of the circuits for a $\mathrm{CPB}$, the activation of inflammatory pathways of coagulation and fibrinolysis remains a major concern for potential pathologic consequences. However, it was argued that OPCABG may cause patients to develop hypercoagulable blood for a short period of time and increase the risk of postoperative thrombotic events (11). Another scholar confirmed that a patient can still be in a hypercoagulable state after 5 days of bypass surgery (12), which may have a certain impact on the free flow rate of grafted vessels (13). Therefore, anticoagulant therapy should be used actively after the operation $(14,15)$. Studies have confirmed that the early application of aspirin after OPCABG can effectively improve the patency rate of grafted vessels, and reduce postoperative complications and mortality (16). The results of the present study revealed that the values of $\mathrm{R}$ and $\mathrm{K}$ were significantly lower at the day of surgery, and at the oral 


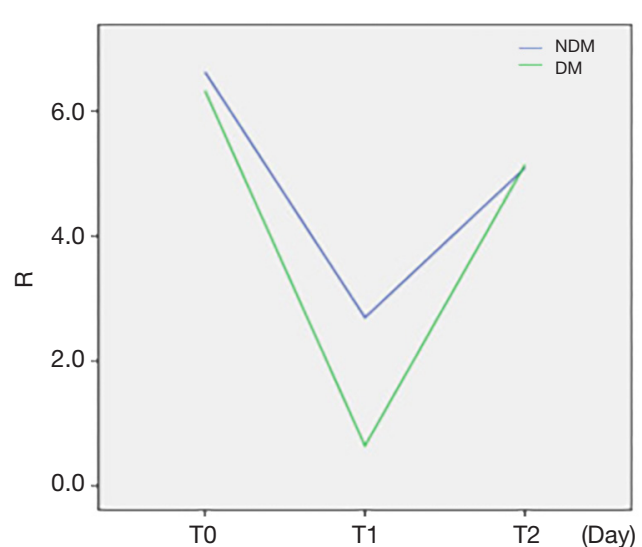

Figure 1 Comparison of $\mathrm{R}$ values at the T0, T1 and T2 time points in the DM and NDM groups. Change rule of the $\mathrm{R}$ value: decreased at the $\mathrm{T} 1$ time point and increased at the $\mathrm{T} 2$ time point, but remained less than that at the T0 time point in both the DM group (green) and NDM group (blue). DM, diabetes mellitus; NDM, non-diabetes mellitus.

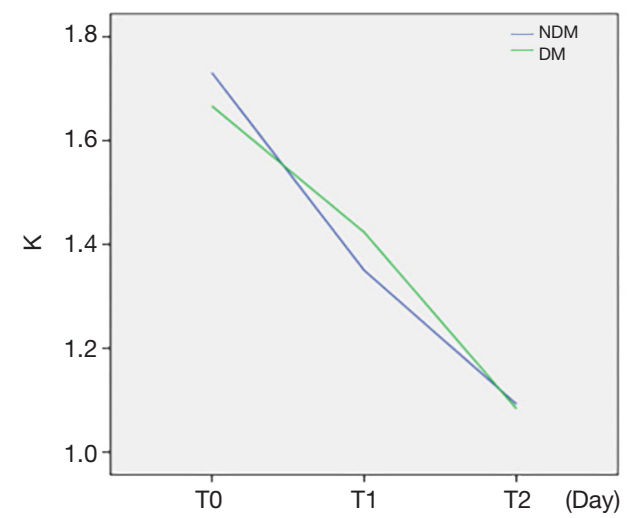

Figure 2 Comparison of $\mathrm{K}$ values at the T0, T1 and T2 time points in the DM and NDM groups. Change rule of the $\mathrm{K}$ value: gradually went down after surgery in both the DM group (green) and NDM group (blue). DM, diabetes mellitus; NDM, nondiabetes mellitus.

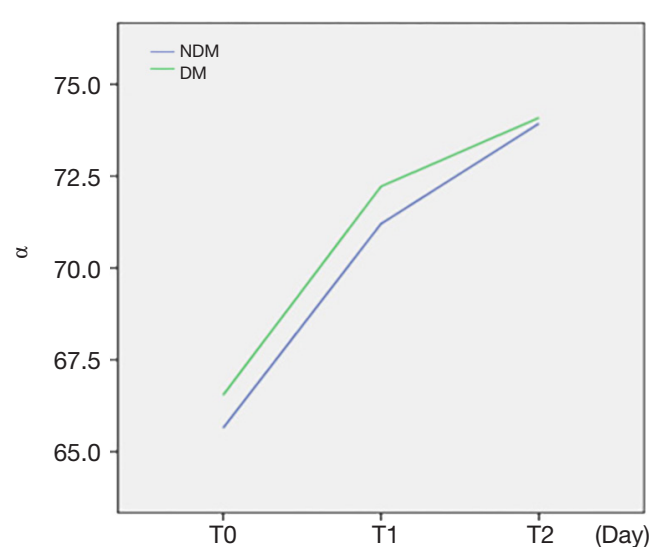

Figure 3 Comparison of the $\alpha$ angle at the T0, T1 and T2 time points in the DM and NDM groups. Change rule of the $\alpha$ angle: gradually increased after surgery in both the DM group (green) and NDM group (blue). DM, diabetes mellitus; NDM, nondiabetes mellitus.

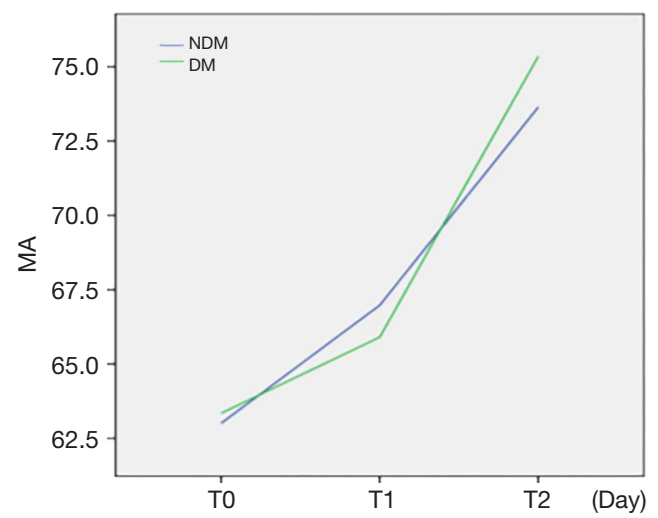

Figure 4 Comparison of MA values at the T0, T1 and T2 time points in the DM and NDM groups $(\mathrm{P}<0.05)$. Change rule of the MA value: gradually increased after surgery in both the DM group (green) and NDM group (blue). DM, diabetes mellitus; NDM, non-diabetes mellitus; MA, maximum amplitude.

Table 2 Comparison of preoperative and postoperative TEG parameters in DM group

\begin{tabular}{lccccc}
\hline Time & $\mathrm{R}(\mathrm{min})$ & $\mathrm{K}(\mathrm{min})$ & $\alpha\left(^{\circ}\right)$ & $\mathrm{MA}(\mathrm{mm})$ & $\mathrm{LY} 30(\%)$ \\
\hline T0 & $6.33 \pm 1.04$ & $1.67 \pm 0.32$ & $66.54 \pm 3.72$ & $63.35 \pm 2.80$ & 0 \\
T1 & $0.64 \pm 0.15$ & $1.42 \pm 0.36$ & $72.22 \pm 3.69$ & $65.90 \pm 4.29$ \\
T2 & $5.14 \pm 0.75$ & $1.08 \pm 0.18$ & $74.09 \pm 2.61$ & $75.35 \pm 3.85$ & 0 \\
F & 484.43 & 29.709 & 40.71 & 87.55 & 0 \\
P & 0.00002 & 0.0008 & 0.0003 & 0.0001 & - \\
\hline
\end{tabular}

TEG, thromboelastography; DM, diabetes mellitus; MA, maximum amplitude. 
Table 3 Comparison of preoperative and postoperative TEG parameters in NDM group

\begin{tabular}{lccccc}
\hline Time & $\mathrm{R}(\mathrm{min})$ & $\mathrm{K}(\mathrm{min})$ & $\alpha\left(^{\circ}\right)$ & $\mathrm{MA}(\mathrm{mm})$ & $\mathrm{LY} 30(\%)$ \\
\hline T0 & $6.63 \pm 1.54$ & $1.73 \pm 0.46$ & $65.64 \pm 5.52$ & $63.01 \pm 7.27$ & $0.03 \pm 0.18$ \\
T1 & $2.70 \pm 2.90$ & $1.35 \pm 0.47$ & $71.20 \pm 4.81$ & $66.98 \pm 5.58$ & $0.06 \pm 0.22$ \\
T2 & $5.10 \pm 0.89$ & $1.09 \pm 0.26$ & $73.93 \pm 2.72$ & $73.64 \pm 5.99$ & $0.08 \pm 0.27$ \\
F & 26.55 & 16.85 & 22.79 & 18.79 & 0.227 \\
P & 0.000 & 0.000 & 0.000 & 0.000 & 0.797 \\
\hline
\end{tabular}

TEG, thromboelastography; NDM, non-diabetes mellitus; MA, maximum amplitude.

Table 4 Comparison of TEG parameters at T0 time point between DM group and NDM group

\begin{tabular}{lccccc}
\hline Group & $\mathrm{R}(\mathrm{min})$ & $\mathrm{K}(\mathrm{min})$ & $\alpha\left(^{\circ}\right)$ & $\mathrm{MA}(\mathrm{mm})$ & $\mathrm{LY} 30(\%)$ \\
\hline $\mathrm{DM}$ & $6.33 \pm 1.04$ & $1.67 \pm 0.32$ & $66.54 \pm 3.72$ & $63.34 \pm 2.79$ & $0.000 \pm 0.000$ \\
$\mathrm{NDM}$ & $6.63 \pm 1.54$ & $1.73 \pm 0.32$ & $65.64 \pm 5.52$ & $63.01 \pm 7.27$ & $0.003 \pm 0.177$ \\
$\mathrm{t}$ & -0.866 & -0.612 & 0.722 & 0.224 & -1.000 \\
$\mathrm{P}$ & 0.39 & 0.543 & 0.473 & 0.824 & 0.327 \\
\hline
\end{tabular}

TEG, thromboelastography; DM, diabetes mellitus; NDM, non-diabetes mellitus; MA, maximum amplitude.

Table 5 Comparison of TEG parameters at T1 time point between DM group and NDM group

\begin{tabular}{lccccc}
\hline Group & $\mathrm{R}(\mathrm{min})$ & $\mathrm{K}(\mathrm{min})$ & $\alpha\left(^{\circ}\right)$ & $\mathrm{MA}(\mathrm{mm})$ & $\mathrm{LY} 30(\%)$ \\
\hline DM & $0.64 \pm 0.15$ & $1.42 \pm 0.36$ & $72.22 \pm 3.69$ & $65.90 \pm 4.29$ & $0.000 \pm 0.000$ \\
NDM & $2.70 \pm 2.90$ & $1.35 \pm 0.47$ & $71.20 \pm 4.81$ & $66.98 \pm 5.57$ & $0.260 \pm 0.219$ \\
$\mathrm{t}$ & 3.611 & 0.659 & -0.893 & 0.813 & 1.341 \\
$\mathrm{P}$ & 0.001 & 0.513 & 0.376 & 0.420 & 0.192
\end{tabular}

TEG, thromboelastography; DM, diabetes mellitus; NDM, non-diabetes mellitus; MA, maximum amplitude.

Table 6 Comparison of TEG parameters at T2 time point between DM group and NDM group

\begin{tabular}{lccccc}
\hline Group & $\mathrm{R}(\mathrm{min})$ & $\mathrm{K}(\mathrm{min})$ & $\alpha\left(^{\circ}\right)$ & $\mathrm{MA}(\mathrm{mm})$ & $\mathrm{LY} 30(\%)$ \\
\hline $\mathrm{DM}$ & $5.14 \pm 0.75$ & $1.08 \pm 0.17$ & $74.09 \pm 2.61$ & $75.34 \pm 3.85$ & $0.000 \pm 0.000$ \\
$\mathrm{NDM}$ & $5.09 \pm 0.89$ & $1.09 \pm 0.20$ & $73.93 \pm 2.72$ & 0.223 & 1.247 \\
$\mathrm{t}$ & 0.23 & 0.178 & 0.824 & 0.219 & 1.436 \\
$\mathrm{P}$ & 0.82 & 0.860 & 0.164 & 0.273 \\
\hline
\end{tabular}

TEG, thromboelastography; DM, diabetes mellitus; NDM, non-diabetes mellitus; MA, maximum amplitude.

administration of aspirin and clopidogrel for five days after surgery, when compared to those before surgery, in both the DM and NDM groups, while the values of MA and $\alpha$ angle significantly increased, indicating that the coagulation function was hypercoagulable at the early period of postoperation. The value of $\mathrm{K}$ gradually decreased after the operation, and the MA value and $\alpha$ angle gradually increased. The results of the present study revealed that there was no statistically significant difference in LY30 between the two groups after OPCABG, which suggests that a hyperthermia function did not emerge. Therefore, it can be concluded that patients with OPCABG are at a high coagulation state 
of different degrees in the early stage after an operation, which could be considered as a period of high incidence of thrombosis. Hence, anticoagulant therapy should be taken seriously to reduce the risk of thrombotic events.

\section{Effect of DM on coagulation function in OPCABG patients}

Recent studies have borne out claims that DM has a significant negative impact on the clinical outcome of coronary surgery in the long term and short term $(17,18)$. In recent years, researchers have gradually realized that the development of diabetes is closely correlated to the imbalance of the coagulation and fibrinolysis system. Studies have found that coagulation function and platelet reactivity increase in patients at the early stage of DM (5). The platelets of patients with DM have their own characteristics. Compared with those without DM, the risk of cardiovascular complications, the recurrence of thrombosis and adverse outcomes is high. Patients with DM exhibit a prothrombotic milieu that consist of hyperreactive platelets (19), which is a tight and rigid clot structure induced by the upregulation of coagulation factors and the prolongation of clot lysis. Metabolic alterations and inflammatory processes, which are upregulated in diabetes, have been considered to be the main underlying causes. Furthermore, the complement cascade has emerged as a potential new player in this context with several complement components directly influencing both platelet function and coagulation (20).

In the present study, TEG parameters before the operation were compared between the NDM and DM groups, but there was no significant difference in the values of $\mathrm{R}, \mathrm{K}, \alpha$ angle and MA, which may be due to the antiplatelet therapy that was regularly combined with medication before surgery. The values of $\mathrm{R}$ and $\mathrm{K}$ were significantly lower at the day of surgery, and at the oral administration of aspirin and clopidogrel for 5 days after surgery, when compared to those before surgery, in both the DM and NDM groups, while the values of MA and $\alpha$ angle significantly increased, which indicate that the coagulation function was hypercoagulable within five days after the operation. In addition, the degree of hypercoagulability was higher in the DM group than in the NDM group at the day of surgery. It can be concluded that patients with OPCABG are at a high coagulation state of different degrees in the early stage after the operation, and patients with DM have more severe coagulation at the day of surgery, which indicate that the coagulation function of patients with DM is more hyperactive than that of patients without of DM.

The present study revealed that the high coagulation state level continued to increase, regardless of the oral administration of aspirin and clopidogrel for five days after surgery, and there was no downward trend. Therefore, it is necessary to closely monitor the blood coagulation function, in order to reduce the occurrence of vascular events.

\section{Weaknesses and limitations of the study}

There were several limitations in the present study. The sample size was small, the number of time points used was few (only three time points), the observation was performed for merely 5 days after surgery, and no long-term follow-ups were achieved. In addition, the angiographic evaluation of the grafts was not performed. In the future, a larger population needs to be assessed to achieve a better understanding of the correlation between DM and coagulation function during OPCABG.

\section{Implication of the study}

TEG can sensitively, accurately and timely reflect the coagulation status of the whole blood, and dynamically monitor coagulation function during the perioperative period. This is helpful for determining the risk of thrombosis, and is of significant value in preventing postoperative thrombosis and thrombosis events.

\section{Unanswered questions and future research}

The correlation between DM and coagulation function during OPCABG remains to be explored in future studies.

\section{Conclusions}

In conclusion, the coagulation function of OPCABG patients presents at a hypercoagulable state at the early stage after an operation. DM affects the coagulation function of OPCABG patients at the day of surgery. OPCABG patients with $\mathrm{DM}$ have more severe coagulation, when compared to patients without of DM, at the day of surgery. However, there was no difference in coagulation function between the two groups after administering oral aspirin and clopidogrel for five days, providing important guidance for the reasonable antiplatelet therapy for OPCABG patients with DM. TEG can sensitively, accurately and timely reflect the coagulation status of the whole blood, 
and dynamically monitor coagulation function during the perioperative period. This is helpful for determining the risk of thrombosis, and is of significant value in preventing postoperative thrombosis and thrombosis events.

\section{Acknowledgments}

None.

\section{Footnote}

Conflicts of Interest: The authors have no conflicts of interest to declare.

Ethical Statement: The authors are accountable for all aspects of this work, in ensuring that questions related to the accuracy or integrity of any part of this work are appropriately investigated and resolved. Scientific research in the present study was approved by the Hospital Ethics Committee (No. W20150217), and patients provided a signed informed consent.

\section{References}

1. Gaudino M, Angelini GD, Antoniades C, et al. Off-Pump Coronary Artery Bypass Grafting: 30 Years of Debate. J Am Heart Assoc 2018;7:e009934.

2. Takagi H, Hari Y, Mitta S, et al. A meta-analysis of $\geq 5$ year mortality in randomized controlled trials of off-pump versus on-pump coronary artery bypass grafting. J Card Surg 2018;33:716-24.

3. Deppe AC, Arbash W, Kuhn EW, et al. Current evidence of coronary artery bypass grafting off-pump versus onpump: a systematic review with meta-analysis of over 16,900 patients investigated in randomized controlled trials. Eur J Cardiothorac Surg 2016;49:1031-41.

4. Hua K, Liu TS, Li Y, et al. Short-term clinical safety and efficacy of No-touch great saphenous vein harvesting technique for off-pump coronary artery bypass grafting. Zhonghua Yi Xue Za Zhi 2018;98:1601-4.

5. Vazzana N, Ranalli P, Cuccurullo C, et al. Diabetes mellitus and thrombosis. Thromb Res 2012;129:371-7.

6. Sarwar N, Gao P, Seshasai SR, et al. Diabetes mellitus, fasting blood glucose concentration, and risk of vascular disease: a collaborative meta-analysis of 102 prospective studies. Lancet 2010;375:2215-22.

7. Pommerening MJ, Goodman MD, Farley DL, et al. Early diagnosis of clinically significant hyperfibrinolysis using thrombelastography velocity curves. J Am Coll Surg 2014;219:1157-66.

8. Gonzalez E, Kashuk JL, Moore EE, et al. Differentiation of enzymatic from platelet hypercoagulability using the novel thrombelastography parameter delta (delta). J Surg Res 2010;163:96-101.

9. Rydén L, Grant PJ, Anker SD, et al. ESC Guidelines on diabetes, pre-diabetes, and cardiovascular diseases developed in collaboration with the EASD: the Task Force on diabetes, pre-diabetes, and cardiovascular diseases of the European Society of Cardiology (ESC) and developed in collaboration with the European Association for the Study of Diabetes (EASD). Eur Heart J 2013;34:3035-87.

10. Roy S, Saha K, Mukherjee K, et al. Activation of coagulation and fibrinolysis during coronary artery bypass grafting: a comparison between on-pump and off-pump techniques. Indian J Hematol Blood Transfus 2014;30:333-41.

11. Quigley RL, Fried DW, Pym J, et al. Off-pump coronary artery bypass surgery may produce a hypercoagulable patient. Heart Surg Forum 2003;6: 94-8.

12. Yachi T, Watanabe G, Tomita S. Activation of coagulation and fibrinolysis after off-pump coronary artery bypass grafting with or without endotracheal general anesthesia. Innovations (Phila) 2010;5:444-9.

13. Takagi H, Tanabashi T, Kawai N, et al. Off-pump coronary artery bypass sacrifices graft patency: metaanalysis of randomized trials. J Thorac Cardiovasc Surg 2007;133:e2-3.

14. Vallely MP, Bannon PG, Bayfield MS, et al. Quantitative and temporal differences in coagulation, fibrinolysis and platelet activation after on-pump and off-pump coronary artery bypass surgery Heart Lung Circ 2009;18:123-30.

15. Desai PH, Kurian D, Thirumavalavan N, et al. A randomized clinical trial investigating the relationship between aprotinin and hypercoagulability in off-pump coronary surgery. Anesth Analg 2009;109:1387-94.

16. Wang Z, Gao F, Men J, et al. Aspirin resistance in offpump coronary artery bypass grafting.Eur J Cardiothorac Surg 2012;41:108-12.

17. Kappetein AP, Head SJ, Morice MC, et al. Treatment of complex coronary artery disease in patients with diabetes: 5 -year results comparing outcomes of bypass surgery and percutaneous coronary intervention in the SYNTAX trial. Eur J Cardiothorac Surg 2013;43:1006-13.

18. Benedetto U, Caputo M, Vohra H, et al. Off-pump versus on-pump coronary artery bypass surgery in patients with actively treated diabetes and multivessel coronary disease. 
J Thorac Cardiovasc Surg 2016;152:1321-1330.e12 .

19. Arthur JF, Jandeleit-Dahm K, Andrews RK, et al. Platelet Hyperreactivity in Diabetes: Focus on GPVI Signaling-Are Useful Drugs Already Available? Diabetes 2017;66:7-13.

Cite this article as: Wang D, Liu Y, Chen Z, Yang F, Zhang $Z$, Wei Y. Impact of diabetes mellitus on coagulation function before and after off-pump coronary artery bypass grafting. J Thorac Dis 2019;11(12):5517-5526. doi: 10.21037/jtd.2019.11.27
20. Hess K. The vulnerable blood. Coagulation and clot structure in diabetes mellitus. Hamostaseologie 2015;35:25-33. 